\title{
Educational Change in Saudi Arabia: Insights from One USA/KSA Teacher Professional Development Collaborative
}

\author{
Adil Bentahar ${ }^{1}$, Kathleen D. Copeland ${ }^{1}$, Scott G. Stevens ${ }^{1,2}$ \& Carol J. Vukelich ${ }^{3}$ \\ ${ }^{1}$ English Language Institute, University of Delaware, Newark, USA \\ ${ }^{2}$ School of Education, University of Delaware, Newark, USA \\ ${ }^{3}$ College of Education and Human Development, University of Delaware, Newark, USA \\ Correspondence: Adil Bentahar, English Language Institute, University of Delaware, 108 E Main \# 204A Newark, \\ DE 19716, USA. E-mail: badil@udel.edu
}

\author{
Received: May 11, $2021 \quad$ Accepted: July 2, $2021 \quad$ Online Published: September 26, 2021 \\ doi:10.5539/ies.v14n10p77 URL: https://doi.org/10.5539/ies.v14n10p77
}

\begin{abstract}
Teacher professional development (PD) programs ideally evaluate how professional learning experiences empower teachers to be effective change agents in their disciplines and communities. The Khbrat ["experiences" in Arabic] program is a year-long, global teacher PD initiative launched by the Saudi Ministry of Education. The goal is to change the mindset of Saudi teachers through immersive experiences in the U.S. K-12 schools and university academic culture so that they can participate as effective "change agents" in the transformation of Saudi schools. Our mixed-methods study examined the impact of the Khbrat program on Saudi teachers' leadership, classroom experiences, and sociocultural levels; the findings inspire new directions for program design with key insights into teacher PD program evaluation.
\end{abstract}

Keywords: educational change, Khbrat, Saudi Arabia, teacher professional development, impact evaluation

\section{Introduction}

Over the last three decades, governments wanting to catalyze major educational reform have created opportunities for teachers to pursue professional development (PD) abroad to gain fresh new perspectives and effect substantive change back home. For example, the Japanese Ministry of Education (MEXT) has offered PD opportunities to teachers (including teachers of English) (Lamie, 2001), and South Korea has funded overseas PD experiences for its secondary teachers. Countries in the Middle East, North Africa (MENA) region have followed the same trend by deploying teacher delegations to English-speaking countries, such as the United States (Allen, 2020; Swain et al., 2003).

In Saudi Arabia, education is considered essential for the kingdom's future success as it transitions from an oil-based to a service economy. Ongoing educational reforms are guided by Saudi Arabia's National Transformation Plan 2020 and Vision 2030, an ambitious social and economic initiative (Al-Maimooni, 2016). Professional development is seen as key to building teacher capacity in order to bring Saudi education into alignment with the larger social vision (Alnahdi, 2014; Al-Zaharni \& Rajab, 2017).

A part of Vision 2030, the Khbrat ["experiences" in Arabic] program, "Building Leadership for Change Through School Immersion," is a yearlong, global teacher professional development initiative launched by the Saudi Ministry of Education in partnership with universities in many English-speaking countries to provide educators essential tools for promoting educational change. The goal of the Khbrat program was to effect a mindset shift of Saudi teachers through immersive experiences in K-12 schools and university academic culture so that they might participate as effective "change agents" in the transformation of Saudi schools and prepare their young population for career success in the global economy of the 21st century (Ministry of Education, 2018).

With worldwide deployment envisioned for thousands of Saudi teachers across a five-year period, by mid-2020, three cohorts totaling approximately 1,000 teachers had completed the Khbrat program in the U.S. (OECD, 2020, as cited in Bentahar et al., 2020). The University of Delaware, through its English Language Institute and School of Education, hosted two cohorts between 2018 and 2020, providing PD for a total of 90 Saudi teachers specializing in a range of academic subjects, including English, math, science, computer science, and Arabic. The current study examined the post-program impact of the university's first cohort of 48 teachers, who completed 
their training year and returned to Saudi Arabia in February 2019.

Following mandates from the Saudi Arabian Ministry of Education, the host program delivered instruction and professional development to enhance teachers' knowledge, skills, values, and attitudes in three major areas: English language development, educational best practices, and school leadership (Ministry of Education, 2018). To meet these goals, the university delivered its program in several overlapping phases. The first six months were devoted primarily to English development, followed by methodological and leadership development through workshops, regional professional conferences, and graduate-level courses. A core component of the program was a K-12 school immersion experience during which teachers observed and researched new teaching approaches along a unique line of inquiry. Finally, university faculty mentors collaborated with and supported the teachers to produce research-based action plans focusing on a practical solution to an identified opportunity for change in Saudi schools. This action plan was expected to be implemented upon their return. Projects were completed with written research papers, portfolios of documentation, and training tools, and were presented in a professional final capstone conference at the University of Delaware for faculty, education graduate students, and surrounding K-12 education communities.

\subsection{Conceptual Framework: Educational Change Management}

As ideas about educational leadership have evolved over the past century, educators must choose from a range of often-divergent theoretical frameworks to design professional development initiatives (Alnahdi, 2014). Added to this challenge is how teachers often perceive a proposed change; a new concept "...which can unsettle assumptions, ask questions of the status quo, and recast our ways of thinking, seeing and doing, [can be] perceived as getting in the way of instrumentalist and/or functional prescriptions of how things ought to be" (Samier \& ElKaleh, 2019, p. v). The researchers of this study observed first-hand how this tension surfaced during this professional development and leadership program. Questions arose throughout their year; "Why should I do this? What real impact will this new approach have on my particular classroom experience? How will these leadership skills lead to change?" These questions warrant evidence-based investigation.

Therefore, with these tensions in mind, the authors approached this study, not within any single conceptual framework, but contextualized within several theoretical frameworks of change management. Kotter's (2007) leadership model of eight phases of change was an integral part of the participants' professional development and is a useful touchstone for how teacher leadership may have manifested itself after the conclusion of the program. Additionally, Rogers' (2003) theory of innovation diffusion and Ely's (1999) conditions of change refer to internal and external factors and are useful for analyzing Saudi educational change efforts (Alsaleh, 2019). Rogers (2003) described internal factors as the characteristics of an innovation itself that may either foster change or generate resistance. External factors relate to the conditions in which an innovation is launched, such as the knowledge and skills of the intended adopters, availability of resources and time, incentives, commitment to participate, and strength of leadership (Ely, 1999). Each of these models highlights planning strategically, securing support and resources, and building incremental momentum to manifest educational change. When examining Saudi Arabia's educational reforms using these models, gaps in effective application of change management practices have been noted, particularly in the implementation and follow-up phases of education initiatives (Alsaleh, 2019).

\subsection{Education Initiatives in Saudi Arabia}

As of 2018, the Kingdom of Saudi Arabia's education system consisted of more than 38,000 schools with 500,000 teachers supporting six million students (Ministry of Education, 2018). A centralized system with a top-down management approach, the Ministry of Education (MOE) sets educational policies and curricula, allocates financial resources, hires staff, and selects and authorizes textbooks (Badawood 2003, as cited in Meemar et al., 2018). The MOE has overseen massive education expansion and significant investment in reforms over the past twenty years to target a shift from an oil-based to a knowledge- and service-based economy, thereby preparing Saudi Arabia's young population for increased global economic competition in the 21st century (Alnahdi, 2014). Incorporating both social and economic initiatives with educational reform at their core, the most recent of these is Vision 2030 (Al-Maimooni, 2016).

Despite huge capital investment by the government, the impact of these initiatives on education outcomes has been limited (Alnahdi, 2014; Alsaleh, 2019). Factors that resulted in reform failure in both Saudi Arabia and the Arab world include "rigidity of top-down management, limited knowledge of effective education reform, lack of an implementation management plan, and lack of professional capacity" of the intended adoptees of reforms (Alsaleh, 2019 , p. 174). Moreover, as the education system sets reform agendas from the top, little to no input appears to have been afforded to important stakeholders, such as teachers, students, and families (Karami-Akkary, 2014; Tayan, 2017). Often, limited information has been distributed about new initiatives and their goals, or about 
expectations of teachers if they choose to participate. Furthermore, because of top-down decision-making, "teachers view change as something that happens to them rather than something that they initiate" (Bashshur, 2005, as cited in Karami-Akkary, 2014, p. 7). Similar sentiments were sometimes voiced by participants of Khbrat Delaware, presenting motivational hurdles to exploring and experimenting with new pedagogical approaches. Alsaleh (2019) asserted that subsequent reform initiatives need a more organized application of change management practices to ensure successful outcomes.

\subsection{Research on the Khbrat Initiative}

Saudi Arabia invested considerable resources in the Khbrat initiative by deploying teachers to university PD programs overseas. A report by the Organization for Economic Cooperation and Development (OECD) on education in Saudi Arabia discussed the program, pointing again to limited review and follow-up of the participants and noting a lack of clarity about "exactly what activities participants engage in and what their impacts are" (OECD, 2020, p. 78).

One study of the Khbrat program conducted by Al-Shehri (2020) focused on English teacher development. However, thousands of Saudi teachers from other disciplines were also deployed through the Khbrat program to English-speaking universities around the globe for professional development. Their PD targeted not only English skill development, but also content instruction, with English being the primary medium of instruction. This aspect of Khbrat highlights its uniqueness among international PD programs. First, the improved English proficiency of teachers of academic content (e.g., math and science) enabled them to access peer-reviewed scientific research, available mostly in English. Furthermore, in providing intensive English instruction to K-12 teachers of other disciplines, the Khbrat program may have helped build broader English exposure into Saudi K-12 learning in potentially more authentic ways, anchoring students for pathways into the increasing numbers of non-western university programs that now incorporate English across the curriculum, particularly in science and engineering, thus requiring a certain level of English proficiency among entering students.

Almoosa (2019) studied the Khbrat program from an administrative stance, seeking to examine the practice of talent management strategies for the professional development of the Ministry of Education in Saudi Arabia. While not addressing its impact on Saudi schools, teaching practices, or leadership development, the study examined data from a random sample of 333 teachers who had completed the program about talent management strategies of "selection, retention, motivation, training and evaluation" (p. 15). Retaining employees (i.e. teachers) and helping them thrive in schools should be a top priority for many governments when planning programs and initiatives, such as Khbrat; furthermore, teacher leaders, as Saudi Arabia's intellectual capital, should be fully supported so that they can showcase their talent and continually develop their skills through teacher professional development (Almoosa, 2019).

Apart from the literature referenced above, peer-reviewed research-based evidence on the overall impact of the Khbrat program appears to be limited. In light of the questions prompted by other researchers and the dearth of peer-reviewed research on the impact of the Khbrat experience, the overarching goal of the current research was to fill a gap and contribute to knowledge about the impact of the Khbrat professional development program on educators' experience after their return to Saudi Arabia, with a focus on the participants' 1) leadership development, 2) teaching techniques, and 3) personal growth.

\section{Methodology}

\subsection{Design and Research Setting}

Using an explanatory mixed methods research design soliciting survey and interview responses, the study explored the perceived impact of the program on 1) the Khbrat educators' leadership and teaching practices, 2) their engagement of the skills, knowledge, and attitudes developed during their year in the United States, and 3) their perception of personal development after returning to their communities at home.

Three research questions guided this study:

1) How did the program prepare participants to return to KSA as educational leaders? What challenges [if any] impeded their action plan implementations?

2) In what ways did participation in the Khbrat program impact Saudi teachers' classroom experiences?

3) What impact did the year-long Khbrat program have on the participants on a socio-cultural level?

To answer these questions, mixed methodological procedures were employed whereby quantitative and qualitative data were collected, analyzed, and then mixed in one study (Creswell \& Plano Clark, 2007; Johnson et al., 2007). The data were collected sequentially (survey responses followed by interview data) nine months after the Khbrat 
educators had returned to Saudi Arabia.

\subsection{Instruments}

The survey (see Appendix A) and interview questions (see Appendix B) were used to uncover the participants' perceived impact of the Khbrat experience in the year following their program. The participants electronically signed an informed consent form and were invited to participate in an optional follow-up interview. Thirty-five $(n=35)$ of 48 completed an online survey, and seven participants participated in the interview.

\subsubsection{Survey}

The survey contained 14 multiple choice and Likert scale questions and several open-ended questions. Some multiple-choice questions included an "other" option to capture participants' responses not included within the multiple-choice options. To ensure the participants' full understanding of the questions and their comfort in responding, the survey questions were delivered in English and in Arabic. To ensure unique responses, respondents were permitted to complete the anonymous survey only once from the same electronic device.

\subsubsection{Interview}

Using a set of predetermined questions created specifically for this study, the semi-structured interviews allowed for follow-up questions, thereby eliciting additional details. The interviewees had the option to respond either in English or in Arabic, as the interviewer is a native speaker of Arabic with mastery of English. The interviews lasted between 18 and 55 minutes and were recorded and transcribed.

\subsection{Participants}

Study participants were members of Cohort 2 of the University of Delaware Khbrat program, having completed their year of training between February 2018 and February 2019. Program participants represented two main instructional categories: English as a Foreign Language (EFL) and academic content areas (ACT), such as math, science, computer science, Arabic language arts, home economics, and art, as well as special needs education. Four of the groups of 48 educators were supervisors of instruction, rather than teachers. Invitations were extended to the 48 cohort members to participate in the study.

\subsubsection{Survey Participants}

Of the 48 Saudi educators, $73 \%(n=35)$ completed the online survey. Of the 35 educators who completed the survey, $51 \%$ were male $(\mathrm{n}=18)$, and $49 \%$ were female $(\mathrm{n}=17)$. Additionally, of these respondents, $57 \%$ were EFL teachers $(n=20)$, and $43 \%$ were ACT teachers $(n=15)$.

Table 1. Khbrat participants' demographic information

\begin{tabular}{cccccc}
\hline Gender & $\%$ & $n$ & Subject Area Taught (Track) & $\%$ & $n$ \\
\hline Male & $51 \%$ & 18 & EFL Track (English as a Foreign Language) & $57 \%$ & 20 \\
Female & $49 \%$ & 17 & ACT Track (Academic Content) & $43 \%$ & 15 \\
Total & $100 \%$ & 35 & Total & 100 & 35 \\
\hline
\end{tabular}

Table 1 presents demographic information collected from respondents on gender and subject area taught (track).

\subsubsection{Interview Participants}

Of the 35 respondents who agreed to complete the survey, 26 (75\%) agreed to take part in semi-structured interviews. The first seven participants $(n=7)$ who agreed to participate were interviewed: five EFL teachers (three male, two female), and two ACT teachers (both female).

\subsection{Data Analysis}

Merging the results of both the quantitative and qualitative data in the analysis phase helped the researchers generate comparisons of responses (Creswell \& Plano Clark, 2011); the merging also enabled an examination of potential areas of data convergence and corroboration (Bowen, 2009). The 35 survey respondents commented in both languages, and the Arabic responses quoted in this study were translated into English by the principal investigator (PI). All translations (English to Arabic on the survey and Arabic into English in the interviews) were verified by an American professor certified in Arabic-English translation. 


\section{Results}

\subsection{Research Question \#1: Impact of Khbrat on Teacher Leadership}

\subsubsection{Successes}

1) Action Plan Implementation. To address the participants' developing roles as educational leaders, the data were gathered through four multiple-choice questions. Three questions addressed the implementation status of the action plans which teachers had developed during their training year. Of the 35 respondents, $71 \%(\mathrm{n}=24)$ indicated that they were implementing their action plans in some way, while $29 \%(\mathrm{n}=11)$ reported they had not begun the implementation process.

Two follow-up multiple-choice questions investigated either how the implementation was progressing or the reasons for not implementing the plan. Of the 24 respondents who indicated some success in implementing their plans, $33 \%(n=8)$ were able to implement exactly as planned, while $67 \%(n=16)$ reported that implementation took place after some modifications to meet new demands or limitations. Half of the respondents reported that their colleagues were applying some of the proposed ideas, and $42 \%$ reported support from supervising administrators. Given that the survey was launched nine months after the program ended, some implementations were moving forward "unofficially," without authorities' approval. Only 13\% $(\mathrm{n}=3)$ reported that they expected to receive monetary recognition for the implementation of the plan they had worked on for a year with extensive government financial support. Figure 1 illustrates these results.

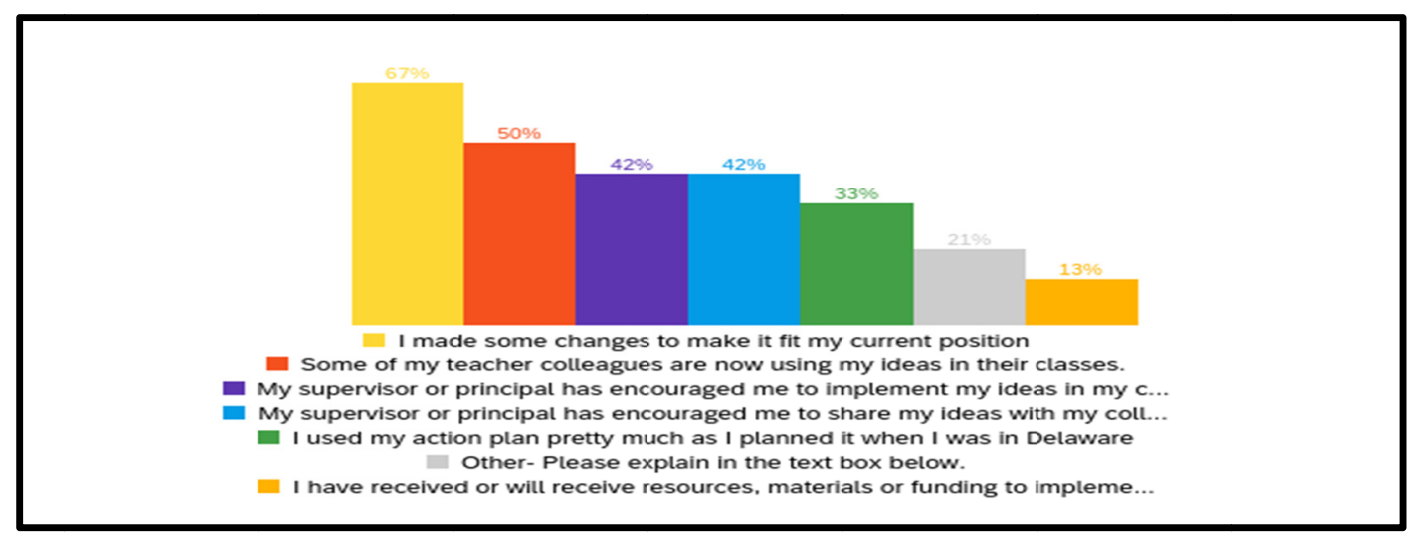

Figure 1. Pathways of Khbrat action plan implementation

2) Developing Leadership. The survey also inquired about other leadership experiences undertaken since returning home. As presented in Figure 2, more than 50\% of the respondents had given either a presentation or a professional development workshop of some kind to their education community. Also, at least $38 \%(n=13)$ served or expected to serve as instructional coaches or mentors. Eighteen percent (18\%) have been invited to serve on committees. Responses also confirmed the promotion of 4 teachers (17\%) to the role of administrator/supervisor. Finally, $18 \%$ reported not participating in any leadership roles at the time of the survey response.

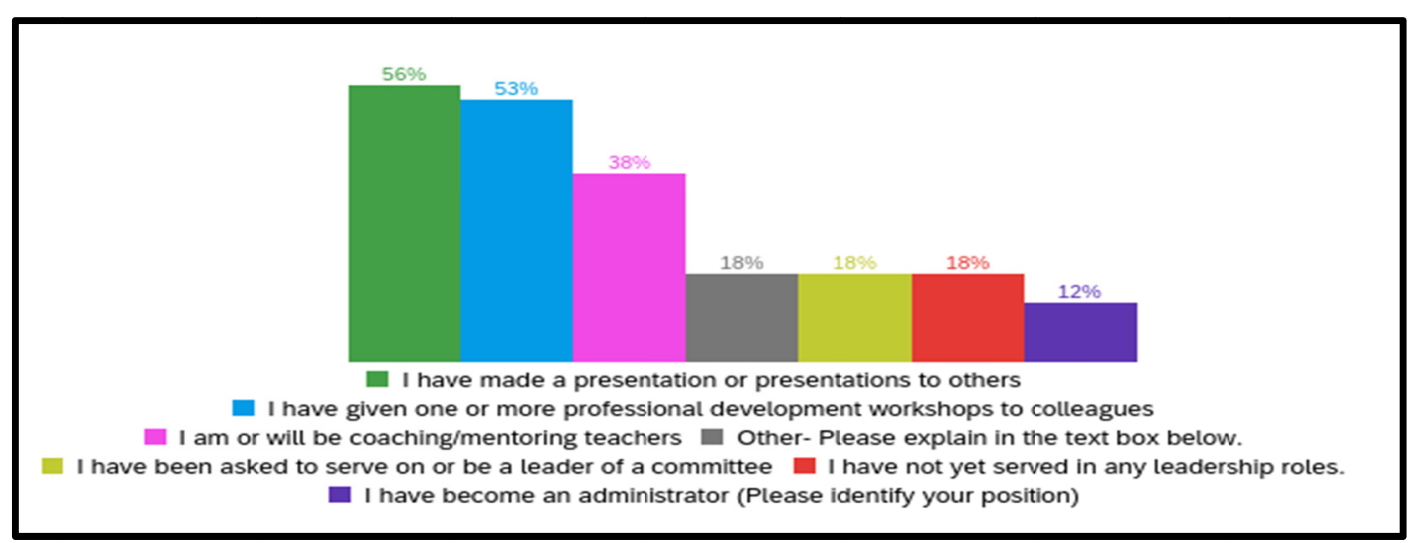

Figure 2. Other leadership roles 
Qualitative findings align with the survey findings in this area. Many teachers reported presenting regionally and nationally as an important pathway for promoting and showcasing their leadership. "After [presenting at] a conference, everyone thinks I am a superstar teacher[,] and my students pride themselves on me, and the school also recognized me [too]." Many also reported administrators' and supervisors' recognition of their potential as current and future leaders. One participant commented, "When they have committees or issues, they ask me to be one of the team. They knew me as a teacher, but now they consider me an expert." Another participant stated that his district expected him to deliver presentations regionally and that "part of my responsibilities is to train other teachers, so I collaborate with the educational training in my district to prepare workshops, training programs and publish." Such comments reflect the recognition and high expectations by some administrators as a result of participation in Khbrat.

The reports of official job promotions and the comments about roles and responsibilities indicate that these Khbrat educators volunteered additional time as mentors to their colleagues, either by request or as a perceived duty of service to their school communities. In comparing responses across gender, the data revealed that more female teachers $(50 \%)$ reported taking on roles as coaches than males $(28 \%)$. Additionally, a high percentage of these educators (58-63\%, EFL; 47\%, ACT) reported giving professional development presentations or workshops. Only $5 \%$ of EFL teachers reported being asked to serve on school committees, as opposed to $33 \%$ of the ACT teachers.

3) Interactions with Colleagues. Respondents were asked to rate changes in interactions with their colleagues. The questions targeted collaboration on teaching approaches of lesson planning, coaching or training colleagues, and perceptions of Khbrat participants as educational leaders. Figure 3 presents the quantitative results for this set of prompts.

Of the 31 teachers, $81 \%(\mathrm{n}=25)$ reported either significant or moderate changes in their interactions with colleagues, while $19 \%(\mathrm{n}=6)$ reported no changes. Further insights into these statements are illuminated in the subsequent comments. For example, $93 \%(\mathrm{n}=29)$ indicated an increase in collaborative efforts with colleagues (a lot: $48 \%, \mathrm{n}=15$; a little: $45 \%, \mathrm{n}=14$ ). One respondent noted, "[My colleagues are now] more open to try[ing] new things..." "Teachers ask [me] about methods and techniques" and "... about things [problems] they face with their students and sometimes we search together to find solutions." Still another participant commented, "I learned the difference between cooperation \& collaboration and how collaboration can make a huge difference." About $84 \%$ of the teachers $(\mathrm{n}=26)$ perceived significant shifts in how their colleagues saw them as educational leaders (a lot: $52 \%, \mathrm{n}=16$; a little: $32 \%, \mathrm{n}=10$, no change $16 \%, \mathrm{n}=5$ ), with an equal percentage reporting some level of opportunity to coach or train their colleagues since returning home ("a lot" and "a little": 42\%, n=13 each).

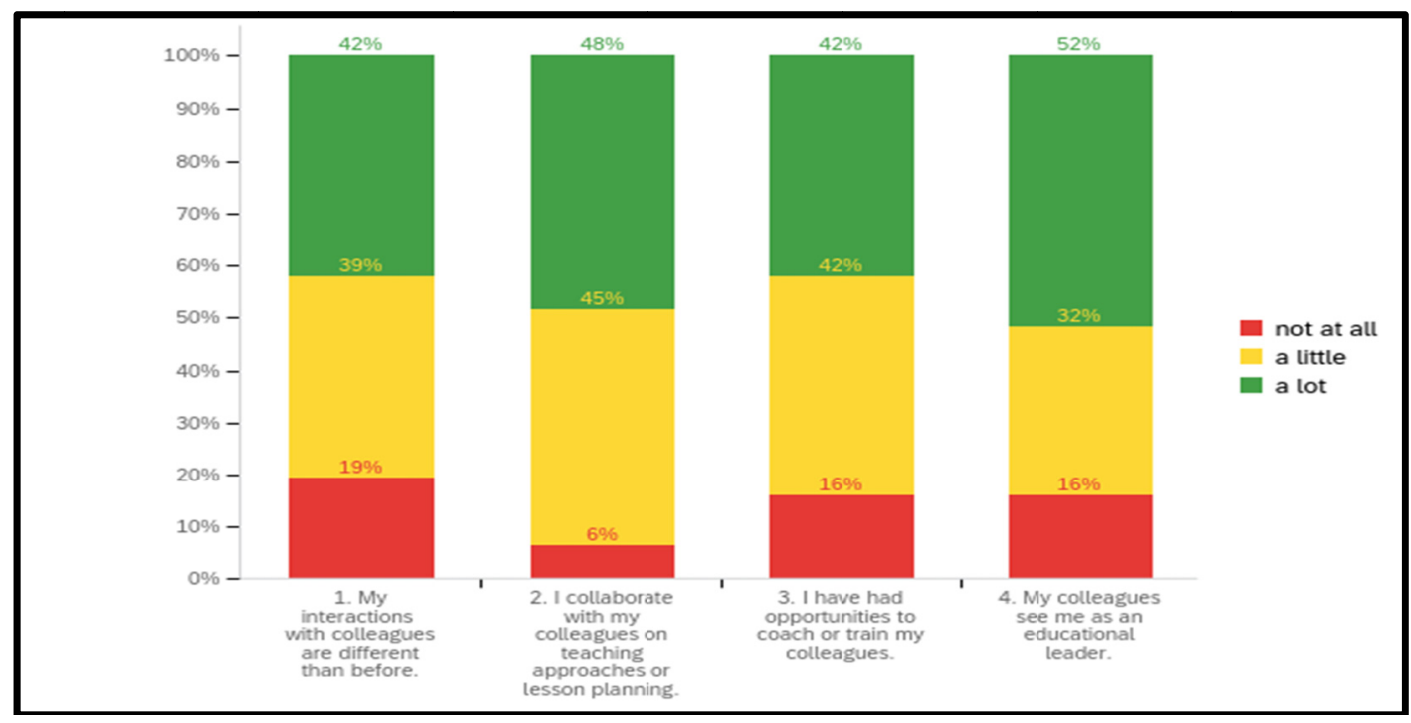

Figure 3. Changes in interactions with colleagues

4) Reignited Passion for Teaching and Leadership. According to open-ended survey and interview responses, participants regarded the program as worthy of the investment of time, citing numerous positive outcomes, including a reignited passion for teaching and readiness to practice leadership. Many reported having rediscovered what made them fall in love with the profession, to begin with. "I also became aware of my teacher leader roles and 
[now] try to emphasize these roles in order to change my colleagues to be better teachers," one participant confirmed. The Saudi educators' quest for educational change was clear in their reported use of classroom best practices and heightened impact on their colleagues. Whether it was through a demonstration lesson, a positive report by a principal or an observer, or a supervisor's or school district official's thank-you letter, more deliberate involvement and leadership across their school communities were reported.

Making a difference appears to be an important facet of post-Khbrat leadership. This aspect of leadership first seems to manifest itself in the classroom and then expands to the larger teacher community, not only by presentations, but also through deliberate interventions to fill instructional or PD-related needs, clarify a concept, or offer evidence-based feedback. "I changed completely not only as a teacher but also in [my] influencing others and making a difference around me." The Khbrat program seems to have helped participants recognize hidden potential as educational leaders and agents of the hoped-for change in their communities, as suggested by the findings of this study. While one participant maintained, "I am now more professional than before," another pointed out, "I followed the same style used with us in Delaware when organizing events/workshops...I offered to become a source for [my colleagues]."

\subsubsection{Challenges}

1) Action Plan Implementation. While some form of resistance from administrators was a common issue, factors such as position changes or difficulty securing project funding represented additional challenges. For the 11 respondents who indicated challenges in moving forward with their action plans, $40 \%(n=5)$ reported that they did not have permission from their supervising administrators to proceed. An additional $40 \%(\mathrm{n}=5)$ reported similar frustrations about lack of support, with one reporting personal challenges. Therefore, the lack of coordinated support from supervising decision-makers (as much as $75 \%$ ) appears to be a major challenge, as presented in Figure 4.

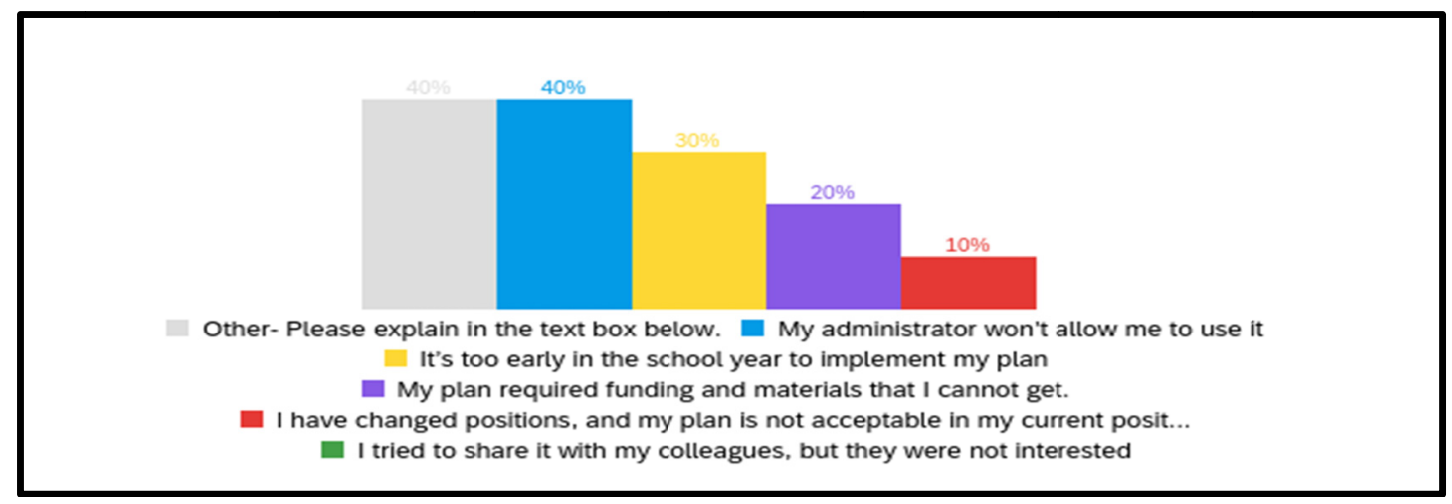

Figure 4. Education action plan implementation challenges

The qualitative results were consistent with the quantitative findings. The theme of challenges reflects two related areas: difficulties in implementing the proposal/action plan and resistance or apathy from colleagues in the workplace.

2) Visibility, resistance, and workload seemed to be the three common challenges reported by the qualitative data. The most common theme in this area was that of returning from a year-long intensely immersive linguistic, cultural, and developmental experience and discovering an absence of sufficient support and planning for their enacting the action plans they had spent months preparing. One of the interviewees stated, "The Ministry of Education doesn't have a clear plan... You have to say, 'I am here. I've learned a lot and want to share."” A similar response was, "You need to step up and tell [the district leaders] who you are, a Khbrat teacher." In short, a number of Khbrat teachers considered their prestigious scholarship award having gone largely unrecognized by their local communities and their newly acquired expertise untapped.

The Ministry of Education groomed Khbrat educators as leaders for change, but many encountered resistance to their ideas by supervisors and officials clinging to the status quo. It was reported that some administrators made little effort to tap into the rich experience and expertise the participants offered their schools. Many Khbrat alumni encountered supervisors who either "move [or] make unkept promises," and all they could do was "keep waiting." Similar indifference arose from colleagues. One participant commented, "With senior teachers, there is always resistance to change." 
Perhaps the most common impediment was workload. After spending one year in the United States, the Saudi educators returned to their home country hoping to have release time to implement their projects. However, many reported finding themselves with the same workload. "I teach 20 classes/week [with] no time to implement my project," one EFL teacher explained. Some administrators appeared to have unrealistic expectations for one scholar to transform the entire faculty without any support or course release. Because of the lack of substitute teacher provisions within the Saudi education system, some teachers taught the regular workload while also offering professional development sessions; "I have to teach the same workload and have to train others, which means I would be absent and have to catch up because there are no [substitutes]."

The researchers also noticed in the findings that there was more resistance by administrators in male schools than in female schools. A full $60 \%$ of male teachers reported not receiving permission from a supervising administrator to proceed with their projects. In contrast, only $20 \%$ of female teachers reported this as a factor. Likewise, $55 \%$ of female teachers who had successfully implemented their projects reported support from their supervising administrators as a factor. On the other hand, only $31 \%$ of male teachers reported support as a factor. Similarly, more ACT teachers seemed to benefit from administrative support than EFL teachers. Between $50 \%$ and $60 \%$ of $\mathrm{ACT}$ teachers reporting success indicated receiving support from their supervising administrators, while only $29-36 \%$ of EFL teachers reported support.

\subsection{Research Question \#2: Impact of Khbrat on Classroom Experiences}

\subsubsection{Perceived Changes in Teaching Approaches}

The first group of prompts on the survey instrument asked teachers to report on changes in the teaching approaches, including statements about interaction with students, classroom management, instructional strategies, diversity in the classroom, special needs, and use of technology (See Figure 5). All the respondents reported that their approaches to classroom management and student interaction had changed either a lot $(71 \%, \mathrm{n}=22)$ or a little $(29 \%, n=9)$. About $90 \%$ reported changes in instructional strategies (a lot: $61 \%, n=19$; a little: $29 \%, n=9)$. More than half $(51 \%, \mathrm{n}=16)$ perceived significant changes in how they addressed different student learning needs, while $42 \%(n=13)$ noted moderate changes. One comment specifically mentioned shifting the focus more toward student needs above curriculum mandates. Finally, changes in technology use for teaching were perceived by $32 \%(n=10)$ to be significant, and by $45 \%(\mathrm{n}=14)$ to be moderate, while a significant $23 \%(\mathrm{n}=7)$ reported no change. The latter finding may be due to a variety of factors, including the lack of financial resources or challenges with technology infrastructure. Less than $10 \%(\mathrm{n}=3)$ reported no changes at all in their instructional approaches after completing Khbrat.

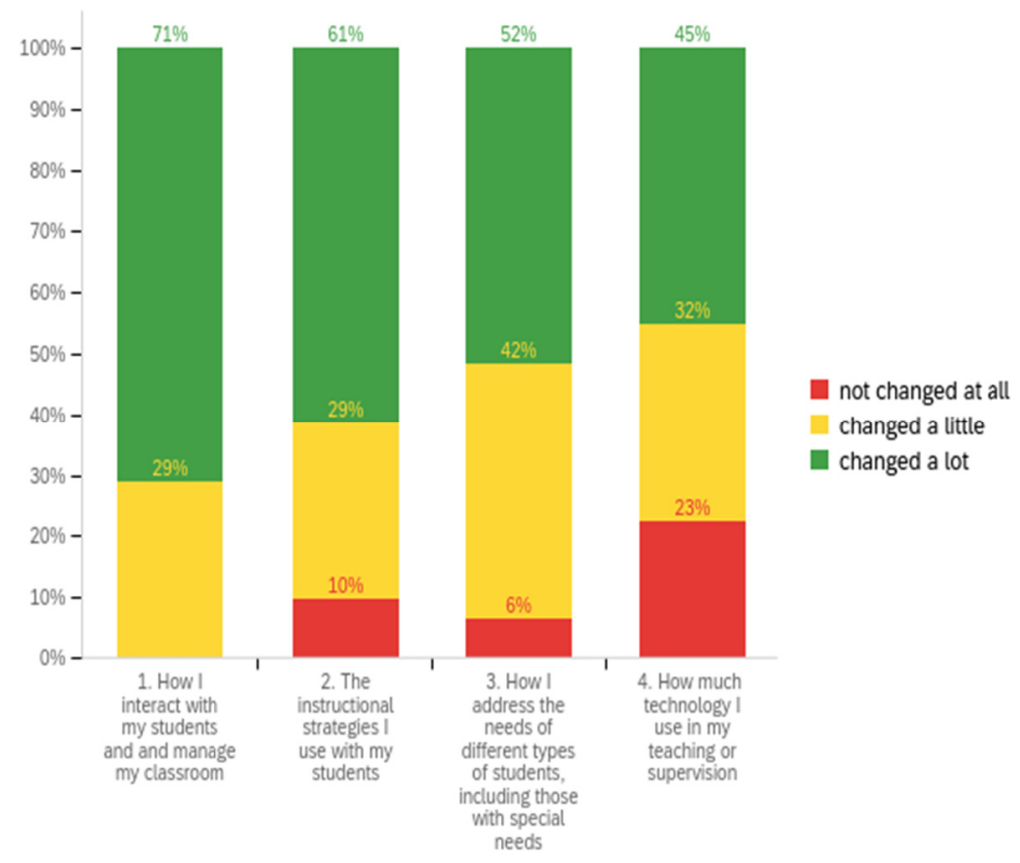

Figure 5. Perceived changes in teaching approaches 


\subsubsection{Perceived Changes in Student Learning Experiences}

An additional set of statements probed changes in student experiences, inquiring about perceived changes in student engagement and motivation, the range of student choice in learning tasks, and students' understanding of expectations. Nearly $94 \%(\mathrm{n}=29)$ reported either significant or moderate changes in both student engagement and motivation (a lot: $48 \%, \mathrm{n}=15$; a little: $45 \%, \mathrm{n}=14$; no change: $6 \%, \mathrm{n}=2$ ) and in students' understanding of expectations (a lot: $68 \%, n=21$; a little: $26 \%, n=14$; no change: $6 \%, n=2$ ). One significant "other" comment mentioned a shift in the roles of students during class. Additionally, the range of student choice in learning tasks was reported to have changed by up to $90 \%$ (a lot: $32 \%, n=10$; a little: $58 \%, n=18$, no change $10 \%, n=3$ ).

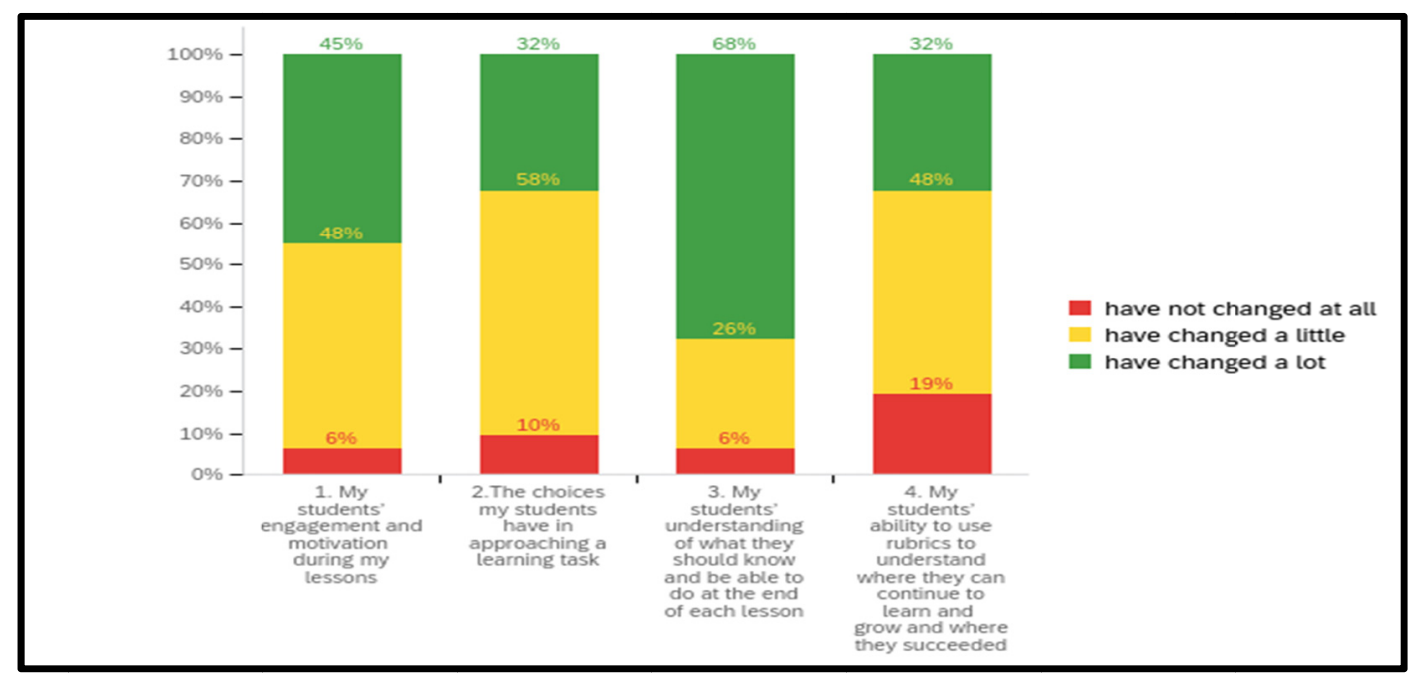

Figure 6. Perceived changes in students' experiences

\subsubsection{Changes in Classroom Practices and Beliefs}

The respondents frequently expressed their restored belief that students' interests should come first, crediting the program with sharpening their instructional tools and practices to better serve students in Saudi schools. The Khbrat program appears to have also impacted teachers' mindsets and boosted their confidence in their students' learning potential and perception of their students' abilities, as reported by the findings. One participant explained, "A lot of my mindset completely changed. I began to accept my students whatever their abilities, colors[,] and races." This participant also started to "attend workshops with other teachers and supervisors to learn new [teaching practices]." Another respondent stated, "[now] I know the right path to proper teaching... I apply with my students what I learned from American schools, and my students are able to create projects weekly."

According to the survey open-ended as well as the interview responses, there seemed to be a marked agreement that participation in Khbrat impacted students' performance positively. One respondent explained, "The [work] environment is still the same, but we're making changes in the teaching, which ultimately impacts students' environment." The data also revealed a change in the tools being considered in evaluating students' progress, including the use of rubrics and checklists.

\subsection{Research Question \#3: The Socio-Cultural Impact of Khbrat}

Unlike the two previous research questions that were supported with data from the survey and interview, responses to research question \#3 were collected primarily from qualitative data (i.e. open-ended survey and interview questions). Responses to the question "Now that you have been home in Saudi Arabia for several months, in what ways did your Khbrat year in the US change you or your family?" addressed the perceived personal and socio-cultural impact of the program on the respondents and their families.

\subsubsection{New Personal Insights}

Saudi Arabia is famous for its rich oral traditions, where one finds passionate and animated debate in the marketplace and in the classroom. Some of the Khbrat participants became avid readers; others struggled with the program's reading load. However, over the course of the year, many came to take great pleasure in reading, both in English and Arabic, and intended to integrate more literacy development into their teaching, as reflected in their 
action plans. The Khbrat teachers also recognized what the data from the host-university program assessments established, that their English had improved markedly. While some participants "created [their own] reading lists to finish reading 50 books in one year," others' success stories focused on their children, who had become avid readers "in English" with one child keeping a "reading log...[from] school and .. reading daily." Perhaps one of the most striking and memorable quotations is the following, "I can say that in one year of Khbrat I read more than what I had read for 8 years on teaching strategies...before Khbrat."

\subsubsection{Self, Family, and Culture}

"I started [to] arrange my priorities both at home and at school."

Apart from professional development, many participants reported personal changes, crediting their exposure to a wide range of cultures and perspectives on education for making them more flexible in their thinking and more open to new ideas. Some interviewees shared how, for example, in the early weeks of their Khbrat year, many participants bristled at what they considered to be the American obsession with arriving, starting, and ending on time. By the end of their stay, however, many had become paragons of punctuality.

One survey question addressed the likely impact of Khbrat on respondents' families. Many mentioned that their children mastered English in no time and that the skills they learned also impacted their family members or companions. One respondent explained, "We're now much more efficient [in maintaining] our family commitments [goals or plans] and self-dependent."

The Khbrat teachers' views of the United States also seem to have changed and become more nuanced. The respondents shared how they found themselves able to move past stereotypes to discover a more complex society, admiring U.S. educational systems and Americans' penchant for organization, innovation, and problem-solving, while also noting the societal issues of racial inequality, secularism, and personal freedom. "We have experienced another way of life and another culture." After the Khbrat year at the University of Delaware, one respondent stated that they had become "a citizen of the world," reporting a transformation into a different person who is "more flexible and tolerant of other cultures, even though I disagree with those cultures and practices." This transformation can only come from an immersive long-term experience in another culture.

Overall, the participants seemed to agree that the Khbrat experience helped them develop new insights into their roles as parents, Saudi nationals, and global citizens, appreciating differences and opportunities around them. As one participant described, "Me [I] and my children [have] become more mind-opening [open-minded] to the other in a different way[s]. We [now] accept the changes that our kingdom [is] go[ing] through with comfort and hope."

\section{Discussion}

Both quantitative and qualitative results support the finding that the participation of these educators in the Khbrat program overall positively affected their leadership development and classroom experiences, despite some challenges reported. Many participants also stood out from day one as change agents and leaders; their impact is manifest not only in how they interact with colleagues and students but also in how they cope with existing impediments.

\subsection{Insights into the Challenges}

Whether providing training for pre-service teachers or professional development for practicing teachers, universities carry the responsibility of helping educators become change agents who can transform classrooms and schools with confidence, despite existing challenges. Such was a critical goal of the Khbrat program, which is probably why the Saudi Ministry of Education collaborated with foreign universities to implement this vision of preparing future education leaders (S. Meemar, personal communication, January 16, 2021). The Khbrat Delaware teachers were asked about the perceived challenges they faced after their return to Saudi Arabia. Our results indicated that while several were awaiting some form of recognition or appreciation reflecting the missing "visibility," others struggled with perceived resistance to their new ideas. Forty percent of the eleven teachers reporting administrative hurdles did not have permission from supervisors to proceed with their projects, which had been supported and funded by the Ministry of Education.

One vitally important step toward growing as change agents is a willingness to rise to these challenges and develop strategies for overcoming them (Kremers et al., 2019). The transformation of the Saudi educators into more focused teachers is also manifest in their persistence, resolve to foster change and perseverance along the way. "In my professional and personal life, I became more persistent, which might [be] seen sometimes as a negative change by others." As one teacher noted, "I've got a very busy schedule but never mind[,] as I have a goal [plan]." One of the fascinating stories stemming from this study is about a teacher whose principal belittles teachers and “doesn't like any kind of change." Instead of giving up, this teacher tried to share the ideas learned from Khbrat, 
but the principal persisted in his unresponsiveness and negative judgment of teachers' capabilities to bring about change. The teacher shifted attention and sought new ears to support her project saying, "However, I transformed [shared] my ideas to two of my colleagues and they like it and [they are now] working with me to [foster] change."

As these emerging leaders began to achieve more recognition after they returned to Saudi Arabia, they felt energized to focus on the needs of their schools and community. This professional development program sought to prepare participants for taking on new roles and seizing leadership opportunities once they were back home. Some have presented at national and international conferences; others have led PD sessions, while still others now serve as go-to teachers when teaching-related issues arise. These instances buoyed their confidence in practicing and sharing leadership with others and emerging as visible leaders and agents of change.

\subsection{Transformation into More Focused Teachers}

For both EFL and ACT teachers, mastery of English came as the result of their assuming the roles of both students and reflective teachers during their stay as program participants. After six months of learning from and observing techniques employed by their ESL teachers, participants gained greater familiarity with new teaching methods and more fluency in communication (speaking and writing) in English. Their enhanced language proficiency also proved critical to their completing major Khbrat assignments in English, including writing a well-researched action plan. Many researchers (e.g., Kurihara \& Samimy, 2007; Liu, 1999) have underscored the value of overseas professional development opportunities and exposure to the target language for teachers, especially second language educators, in terms of developing professional expertise, communicative competence, and an "understanding of innovative teaching methods" (Kurihara \& Samimy, 2007, p. 100). The latter goals are at the heart of the Khbrat program in that the educators are now relying on the knowledge, skills, and attitudes they developed to showcase not only teaching innovations but also effective professional dispositions. "My students feel there is good teaching and therefore respect me more now because they see the difference," one participant explained.

Programs like Khbrat can have a major impact on teachers' and, ultimately, students' performance. Because of Khbrat, some language teachers remarked how their "students' reading and pronunciation and speaking improved." Others discovered the concept of rubric and learning styles for the first time and transferred their knowledge to Saudi language classrooms and shared it with colleagues. Still other teachers wanted to help their students give their full potential and improve their learning outcomes, which did not seem to be a priority for many before Khbrat. One teacher commented,

Two years ago, I thought when students don't want to study, I let go.

I give up and say, 'You don't have to do anything.' This is a mistake

teachers make. Now, I believe teachers should change the thoughts of

their students.

Growing aware of the students' needs and the teacher's responsibility to go beyond merely addressing their learning outcomes, seemed to be an aha moment for many teachers, which they credited to their Khbrat experience. "Now, I ask my students about homework and collaborate and speak and write to and about others. Before KT [Khbrat], I believed that there was no benefit for students to try," another teacher reflected.

The passion of Khbrat program alumni for professional growth proved contagious. The participants reported increased rates of student engagement, as they responded favorably to new methods and approaches employed following the return to Saudi Arabia. The respondents acknowledged a paradigm shift in their approach to teaching; they reported being less preoccupied with meeting arbitrary district requirements and more focused on individual learner needs that translated into articulating clearer learning outcomes and the strategies for meeting them. Some pursued action research, documenting student progress and the impact of various instructional strategies as a means of informing their more reflective approach to teaching. Given the correlation between teacher productivity and professional development and improved student learning and academic achievements (Harris \& Sass, 2011), it is commonplace that many Khbrat teachers now prioritize student learning over other considerations (e.g., curriculum).

The Khbrat program philosophy starts with a premise that community leadership and change promotion in the community begin from the classroom and school walls. A simple Google search of "Khbrat universities leadership" resulted in about 667 results, most of which emphasize building leadership for change through school immersion. Although located in nine countries, each Khbrat host university shares identical program goals (Alabdali, 2018). 


\section{Recommendations}

This study yielded a range of insights that may inform the design and delivery of international teacher professional development programs such as the Khbrat program, and may also apply to a wider range of professional development initiatives. From these insights, the authors propose, with appropriate qualifiers, the following recommendations.

\subsection{Use Backward Design}

As Stephen Covey (2004) put it, "Begin with the end in mind." By clearly articulating the end goals of the proposed initiative, program designers can build in key steps and support to ensure careful planning, orientation, delivery, and, above all, follow-up. Backward design may, for example, help planners anticipate the resistance a single returning teacher encounters attempting to effect change, and conclude that selecting at least two teachers from every school may prove more impactful.

\subsection{Impart the Vision at All Phases}

Beginning with the trainee application, teachers competing for scholarships will benefit from understanding and embracing the project's vision. Underscoring this vision should be a central mission of pre-departure orientations and of every phase of a training project. When participants arrive at their host university fully understanding their mission, the enormous investment of energy and time can be fully operationalized through commonly shared expectations and goals, thereby sustaining group morale and motivation throughout the training period to the implementation of participants' projects at home.

\subsection{Prepare the Soil}

Pre-departure orientations are the ideal time to equip participants for their challenge ahead by providing an in-depth understanding of their host culture; clarifying their sponsor's expectations in terms of effort, time on task, and support for the program's goals; building a bond of mutual respect and support among cohort members; and even prior to departure, reflecting on areas of teaching they wish to impact in consideration of their final project. Furthermore, sponsors can also "prepare the soil" for the participants' return so that program investment can have the desired impact; ministry officials can reach out to school administrators and impart the vision to them as well.

\subsection{Support the Vision}

Supporting the vision involves empowering teachers in which the sponsors have invested to succeed in fulfilling the project's goals. This success is dependent on sponsors providing returning teachers the resources and backing of colleagues and superiors to put their ideas into practice, and ensuring ample release time to implement their projects and conduct school-based professional development. This is the most critical phase of training projects, and as the authors' review of the literature indicates, often the most neglected.

\subsection{Elevate the Educators}

Program sponsors would do well to recognize, celebrate, and elevate the alumni of the professional development programs in which they have invested. Ideally, sponsors would organize regional and national conferences, establish networks among training alumni to collaborate and refine their ideas and allow the impact of their experience to expand across the educational system.

\subsection{Plan for the Assessment of the Project}

Thoughtful consideration should be given to the design of assessment of a training project's impact. Evaluations aimed narrowly at short-term gains in student or program participant scores in national exams can entirely miss the mark. Education reforms may be more effectively evaluated through qualitative measures of training impact, such as examining student engagement and interest in learning and nurturing and empowering learning environments. Although changes in attitudes, values, and paradigms are not easily quantified, they are often the most important changes of all.

\section{Limitations}

There were limitations in this study in that it would be challenging to claim the generalizability of the results to all Khbrat host universities or partners. Additionally, the findings were collected from a single cohort; therefore, a comparative study looking at the same areas of impact from additional cohorts might yield more generalizable findings worth investigating to determine if these results are representative.

\section{Conclusion}

The findings of this study offer unique insights into the post-program experiences of the Saudi educators at a time when little research exists about the Khbrat program; this study sheds light on the direct impact of this university's 
program on their personal, professional, and leadership development. As such, this study represents new ground in empirical research on the potential long-term impact of the Khbrat program overall. Findings may potentially inform new directions in planning and designing future international teacher professional development and leadership programs of this scope.

\section{References}

Alabdali, M. (2018, July 4). 8 objectives provided by Khebrat in 9 countries around the world. Alwatan Saudi Newspaper. Retrieved from https://www.alwatan.com.sa/article/380840/8-

Allen, N. (2020, March 25). Teachers collaborating across borders (TCAB): Online program for US and Middle East/North Africa teachers. UNC World View. University of North Carolina at Chapel Hill. Retrieved from https://worldview.unc.edu/news-article/teachers-collaborating-across-borders-tcab-online-program-for-us-a nd-middle-east-north-africa-teachers/

Al-Maimooni, M. (2016). The Deputy Crown Prince reveals 13 national initiatives for kingdom's future Vision 2030. Al Yaum Newspaper. Retrieved from http://www.alyaum.com/article/4133366

Almoosa, N. A. (2019). The degree of practicing talent management strategies in the program of Experiences of qualitative professional development at Saudi Ministry of Education from the scholarship students' point of view. The Arabian Gulf Message, 153, 15-43. Retrieved from https://library.abegs.org/journal/rpc/ download/AMIfv965VBv6d6IopeYCWjyhHfxsypu6CEAuMoYvOdIsiVfqy0XLkdQcqHoXo6ogPvvCEz8u igICNxfdP4VqqVS4LuNX9uZf35UPtUtVLMupo6J6GHC0Of81lcORxGjxWxrLpu66CQsUV_iTddcUimT O7VJX11GitF5mPddMn5ZhUhxWB3tovGk

Alnahdi, G. H. (2014). Educational change in Saudi Arabia. Journal of International Education Research, 10(1), 1-6. https://doi.org/10.19030/jier.v10i1.8342

Alsaleh, B. A. (2019). K-12 education reforms in Saudi Arabia: Implications for change management and leadership education. In Teaching Educational Leadership in Muslim Countries (pp. 171-186). Springer Nature Pte Ltd. https://doi.org/10.1007/978-981-13-6818-9_10

Al-Shehri, S. (2020). Transforming English language education in Saudi Arabia: Why does technology matter? International Journal of Emerging Technologies in Learning, 15(6), 108-123. https://doi.org/10.3991/ijet.v15i06.12655

Al-Zahrani, N. O. A., \& Rajab, H. (2017). Attitudes and perceptions of Saudi EFL teachers in implementing Kingdom of Saudi Arabia's Vision 2030. International Journal of English Language Education, 5(1), 83-99. https://doi.org/10.5296/ijele.v5i1.10733

Badawood, O. (2003). The development of leadership skills of private high school principals in Jeddah, Saudi Arabia (Unpublished doctoral dissertation). University of Pittsburgh.

Bashshur, M. (2005). Dualities and entries in educational reform issues. In A. El Amine (Ed.), Reform of general education in the Arab world (pp. 277-298). UNESCO Publications.

Bentahar, A., Copeland, K., \& Vukelich, C. (2020, January 7). Preparing Saudi educators for school leadership: One Khbrat program in the U.S. [Conference session]. 33rd International Congress for School Effectiveness and Improvement (ICSEI), Marrakech, Morocco.

Bowen, G. A. (2009). Document analysis as a qualitative research method. Qualitative Research Journal, 9(2), 27-40. https://doi.org/10.3316/qrj0902027

Covey, S. R. (2004). The 7 habits of highly effective people: Restoring the character ethic. Free Press.

Creswell, J. W., \& Plano Clark, V. L. (2007). Designing and conducting mixed methods research. Sage.

Creswell, J. W., \& Plano Clark, V. L. (2011). Designing and conducting mixed methods research (2nd ed.). Sage.

Ely, D. P. (1999). New perspectives on the implementation of educational technology Innovations. Educational Resources Information Center [ERIC], 142, 1-15.

Harris, D. H., \& Sass, T. (2011). Teacher training, teacher quality and student achievement. Journal of Public Economics, 95(7-8), 798-812. https://doi.org/10.1016/j.jpubeco.2010.11.009

Johnson, R. B., Onwuegbuzie, A. J., \& Turner, L. A. (2007). Toward a definition of mixed methods research. Journal of Mixed Methods Research, 1(2), 112-133. https://doi.org/10.1177/1558689806298224

Karami-Akkary, R. K. (2014). Facing the challenges of educational reform in the Arab world. Journal of Educational Change, 15, 179-202. https://doi.org/10.1007/s10833-013-9225-6 
Kotter, J. (2007). Leading change: Why transformation efforts fail. IEEE Engineering Management Review, 37(3), 42-48. https://doi.org/10.1109/emr.2009.5235501

Kremers, A. S., Liepins, A. S., \& York, A. M. (2019). Developing change agents: Innovative practices for sustainability leadership. Minnesota Libraries Publishing.

Kurihara, Y., \& Samimy, K. K. (2007). The impact of a U.S. teacher training program on teaching beliefs and practices: A case study of secondary school level Japanese teachers of English. JALT Journal, 29(1), 99-122. https://doi.org/10.37546/jaltjj29.1-5

Lamie, M. J. (2001). Understanding change: The impact of in-service training of teachers of English in Japan. Science Publishers, Inc.

Liu, D. (1999). Training nonnative TESOL students: Challenges for TESOL teacher education in the West. In G. Braine (Ed.), Nonnative educators in English language teaching (pp. 197-210). Lawrence Erlbaum.

Meemar, S. S., Poppink, S., \& Bierlein Palmer, L. (2018). Educational decentralization efforts in a centralized country: Saudi Tatweer principal perceptions of new authorities granted. International Journal of Education Policy and Leadership, 13(2), 1-15. https://doi.org/10.22230/ijepl.2018v13n2a730

Ministry of Education. (2018). Request for proposals: Building leadership for change through school immersion. Riyadh, Saudi Arabia.

Organization for Economic Cooperation and Development. (2020). Education in Saudi Arabia. Reviews of National Policies of Education, 1-221. OECD Publishing, Paris. https://doi.org/10.1787/76df15a2-en

Rogers, E. M. (2003). Diffusion of innovations. Free Press.

Samier, E. \& ElKaleh, E. (2019). Teaching educational leadership in Muslim countries: Theoretical, historical and cultural foundations. Springer Nature. https://doi.org/10.1007/978-981-13-6818-9

Swain, J., Monk, M. \& Ghrist, M. (2003). The overseas in-service Egyptian teacher education programme: Distal and proximal reflections on policy and change. Journal of In-Service Education, 29(1), 61-80. https://doi.org/10.1080/13674580300200261

Tayan, B. M. (2017). The Saudi Tatweer education reforms: Implications of neoliberal thought to Saudi education policy. International Education Studies, 10(5), 61-71. https://doi.org/10.5539/ies.v10n5p61

\section{Appendix A}

\section{Khbrat Participant Demographics}

1. I came to Khbrat (name of state) in 2018 as a ... Teacher Administrator/Supervisor

2. In the Khbrat (name of state) program I was in the... EFL Track (English as a Foreign Language) ACT Track (Academic Content Teacher)

3. I am a... male female

4. Right now I work as a ... Teacher Administrator/Supervisor Other Please explain.

5. Right now I work at... A school, as a teacher A school, not as a teacher A private business 
Education district office

Ministry of Education Central Administration

Other Please explain.

\section{Impact on Employment}

6. For teachers: When you finished the Khbrat program, did you return to the same job and school you had before the Khbrat experience, or did you get a new job assignment?

I am a teacher in the same school.

I am still a teacher, but in a different school.

Iamnolongerateacher.Inowama

7. If your job responsibilities have changed, please describe how your job responsibilities have changed.

8. If you work in a new school, is it nearer, farther, or the same distance from your home as your previous school was?

Nearer

Farther away

About the same distance

9. For supervisors/administrators: When you finished the Khbrat program, did you return to the same job, or did you get a new job assignment?

I do the same job in the same office/district.

I do the same job, but in a different office or district.

Ihave a differentjobnow. Please provide yournew title.

10. If your job responsibilities have changed, please describe how your job responsibilities have changed.

\section{Impact on Educational Leadership}

During your Khbrat (name of state) program, you gathered professional development tools and also created an action plan/final project for making a change in your school community. Please answer the following questions about your experience implementing these ideas in Saudi Arabia.

11. Have you used or are you now using any part of your action plan/final project since you returned to Saudi Arabia?

Yes

No

12. IF YOU HAVE USED OR ARE USING YOUR ACTION PLAN/FINAL PROJECT, please check all that apply:

I used my action plan pretty much as I planned it when I was in (name of state)

I made some changes to make it fit my current position

Some of my teacher colleagues are now using my ideas in their classes.

My supervisor or principal has encouraged me to implementmy ideas in my class.

My supervisor or principal hasencouragedmeto sharemyideas withmy colleagues.

I have received or will receive resources, materials or funding to implement my plan.

Other. Please explain

13. IF YOU HAVE NOT USED YOUR ACTION PLAN/FINAL PROJECT, please tell us why (Check all that apply.) (If you have used your action plan, skip to the next question).

I have changed positions, and my plan is not acceptable in my current position

My administrator won't allow me to use it

I tried to share it with my colleagues, but they were not interested

It's too early in the school year to implement my plan 
My plan required funding and materials that I cannot get.

Other. Please explain

14. Have you been asked to serve in any leadership roles? (Please check all that apply)

I have made a presentation or presentation to others

Ihave given one or more professional development workshops to colleagues

I have been asked to serve on or be a leader of a committee

I have become an administrator (Please identify your position_)

I am or will be coaching/mentoring teachers

Other. Please describe

\section{Impact on Teaching Experience}

15. Please rate how your teaching approaches have changed in these areas after youryear in the US: (Please put a mark on the line to indicate your response.

$$
\text { Not at all ------to ---- a lot }
$$

How I interact with my students and manage my classroom

The instructional strategies I use with my students

How I address the needs of different types of students, including those with special needs

How much technology I use in my teaching or supervision

Other. Please explain.

16. Please rate your interactions with your colleagues in these areas after your year in the US: (Put a mark on the line to indicate your response).

Not at all ------to ---- a lot

My interactions with colleagues are different than before.

I collaborate with my colleagues on teaching approaches or lesson planning.

I have had opportunities to coach or train my colleagues.

My colleagues see me as an educational leader.

Other. Please explain.

17. Please rate how your students' experiences may have changed after your year in the US: (Place a mark on the line to indicate your response).

My students' engagement and motivation during my lessons

The choices my students have in approaching a learning task

My students' understanding of what they should know and be able to do at the end of each lesson

My students' ability to use rubrics to understand where they can continue to learn and grow and where they succeeded

$$
\text { Not at all -----to ---- a lot }
$$




\section{Cultural Impact}

18. Now that you have been home in Saudi Arabia for several months, did your Khbrat year in the US change you or your family? If so, please describe the changes you have noticed.

19. Please feel free to leave any additional comments about how your Khbrat year in the US may have impacted you personally and culturally through your experience of social interactions in Saudi Arabia, or any other life experiences. All comments are anonymous and completely confidential.)

\section{Recommendations:}

The Khbrat (name of state) team asked you these questions at the end of your program. Now that you have been home for several months, we would like to ask you again:

20. Is there anything that Khbrat (name of state) could have done to make your program experience more useful for you? Please explain.

21. Is there anything that the Ministry of Education could have done, or could do now, to make your Khbrat experience more useful for you? Please explain.

Thank you for your participation!!

\section{Appendix B}

Semi-Structured Interview Questions Administered to Saudi Educators ( $\mathrm{n}=4-8)$

1) Were you able to implement your action plan/project? If yes, please tell me about what you did, the responses from stakeholders involved (e.g., students and colleagues), and how successful it was.

2) If you were NOT able to implement your action/project, please tell me about why you have not been able to implement your action plan/project. Is there a time in the future when you might be able to implement your action plan/project? Please explain.

3) Tell us about the challenges [if any] that you faced during implementation of your project.

4) Please tell us about the leadership role you have assumed. What have you been asked to do that you didn't do before your Khbrat experience?

5) How did your Khbrat experience change how you approach your students or your colleagues? Tell us how the experience had or did not have an impact on your classroom experience in general. Please elaborate.

6) Did the Khbrat experience have any impact on you or your family? If so, please explain.

7) Is there anything else you would like to share with me? Please share.

Thank you for your participation. 


\section{Copyrights}

Copyright for this article is retained by the author(s), with first publication rights granted to the journal.

This is an open-access article distributed under the terms and conditions of the Creative Commons Attribution license (http://creativecommons.org/licenses/by/4.0/). 